\title{
AVALIAÇÃO DO TIPO DE AGLUTINANTE NA RESISTENCIA A COMPRESSÃO DO CARVÃO VEGETAL OBTIDO PELA PIRÓLISE DO BAGAÇO DE LARANJA
}

\author{
V. O. CONCENTINO ${ }^{1}$, K. ZANELLA ${ }^{1}$ e O. P. TARANTO ${ }^{1}$ \\ ${ }^{1}$ Universidade Estadual de Campinas, Faculdade de Engenharia Química \\ E-mail para contato: vini.concentino@gmail.com
}

\begin{abstract}
RESUMO - O Brasil possui grande potencial para o aproveitamento de resíduos agrícolas no processo de conversão termoquímica, como é o caso dos resíduos sólidos do processamento da laranja. A aplicação da carbonização converte o bagaço da laranja a carvão vegetal. Para sua transformação em briquetes é preciso realizar a etapa de densificação energética, processo no qual é necessária a adição de um aglutinante visando o aumento da resistência mecânica à compressão do briquete de carvão vegetal. Este estudo teve como objetivo principal verificar a influência do tipo de aglutinante (pectina $30 \%$, pectina $65 \%$ ou amido de milho) na resistência à compressão do briquete de carvão vegetal, produzidos a partir da carbonização do bagaço da laranja. Para os ensaios de compressão, briquetes com $10 \%\left(\mathrm{~m}_{\mathrm{ag}} / \mathrm{m}_{\mathrm{car}}\right)$ de aglutinante foram produzidos. Os resultados indicaram que o aglutinante que proporcionou um briquete com maior resistência a compressão foi o amido de milho (3,360 MPa), seguido da pectina 30\% (2,117 MPa) e da pectina $65 \%(1,776 \mathrm{MPa})$.
\end{abstract}

\section{INTRODUÇÃO}

O Brasil se destaca como um país com grande potencial para o aproveitamento de biomassa no processo de conversão termoquímica, sobressaindo-se os resíduos agrícolas (Alho, 2012). Dentre destes, destacam-se os resíduos sólidos do processamento do suco de laranja (bagaço da laranja). Logo, a busca pela utilização destes resíduos como subprodutos, torna-se interessante. Uma alternativa à sua aplicação seria a aplicação da carbonização nos resíduos sólidos. Segundo Tienne et al., (2004), esta técnica converteria o bagaço da laranja a carvão vegetal e ao mesmo tempo, facilitando o seu transporte, armazenamento e manuseio. A carbonização possui como objetivo principal a obtenção da fase sólida nos produtos finais (carvão). Para a transformação destas partículas em briquetes faz-se necessário a etapa de densificação energética, a qual concentra a energia disponível.

As partículas de carvão vegetal são compostas por carbono, material sem um mecanismo de ligação adequado, quando compactado, para a produção de briquetes. Por isso, a maior dificuldade na produção de briquetes é justamente a busca de um aglutinante que promova as características necessárias que um briquete de boa qualidade deve possuir (De Oliveira, 2013). Os aglutinantes funcionam como adesivo e contribuem para a interligação das partículas. Para amenizar essas características negativas das partículas de carvão vegetal, opta-se pela densificação energética. A densificação energética (briquetagem) é uma técnica resultante da aplicação de certa pressão, em uma mistura de partículas de material sólido com 
um aglutinante, dentro de moldes matrizes, com o objetivo de formar blocos compactos e com elevada resistência mecânica. A resistência à compressão é um parâmetro significativo na avaliação do briquete ao seu armazenamento. Com o intuito de avaliar a influência das forças aplicadas na etapa de densificação energética, a resistência dos briquetes à compressão é determinada para prever o comportamento mecânico dos briquetes quando submetido a uma determinada carga ou esforço, considerando sua posição de armazenamento (Dias et al., 2012).

Mais de 50 ligantes orgânicos e inorgânicos vêm sendo empregados na densificação energética, sendo os mais comuns no Brasil o amido de milho, a fécula de mandioca, resinas sintéticas, alcatrão vegetal, o melaço de cana-de-açúcar e a bentonita (Fontes et al., 1989; Dias et al., 2012). A busca por novos aglutinantes vem se intensificando, principalmente para utilizar o mínimo possível deste material, desde que seja atendido aos requisitos necessários de um briquete de alta qualidade (Dias et al., 2012). A pectina é um polissacarídeo obtido principalmente da casca de frutas cítricas. Este carboidrato é solúvel em água, que quando submetidos a condições adequadas tem a capacidade de formar gel. De acordo com Tumuluru et al. (2011), a pectina é considerada como sendo um aglutinante natural da biomassa. Desta forma, é de grande interesse que se analise o uso da pectina como aglutinante na produção de briquetes com qualidades específicas para uso doméstico e comercial.

Diante do exposto, este trabalho tem como objetivo principal o estudo de dois novos aglutinantes, a pectina de alto teor de metoxilação (65\%) e a pectina de baixo teor de metoxilação (30\%), na resistência a compressão mecânica dos briquetes de carvão vegetal, produzidos através da carbonização do bagaço da laranja. Para comparações, briquetes também foram produzidos com um aglutinante já aplicado, o amido de milho industrial.

\section{MATERIAIS E MÉTODOS}

\subsection{Preparação e Carbonização do Bagaço da Laranja}

O bagaço de laranja passou primeiramente por um processo de cominuição, separado em pedaços de cerca de $1,0 \mathrm{~cm}^{2}$. O sistema de pirólise em leito fixo é composto de uma mufla, com suprimento de oxigênio limitado e com saída de gases. Estes gases passam por um filtro de algodão, para reter possíveis partículas e posteriormente são liberados para a atmosfera.

A metodologia de pirólise lenta, utilizada por Alho (2012) foi aplicada neste estudo. A amostra previamente desidratada em estufa a $105^{\circ} \mathrm{C}$ foi colocada dentro da mufla. Uma taxa de aquecimento de $10{ }^{\circ} \mathrm{C} / \mathrm{min}$ foi aplicada até atingir a temperatura de $450{ }^{\circ} \mathrm{C}$, permanecendo nesta temperatura por 60 minutos. Após o término do processo, a biomassa carbonizada foi retirada da mufla e colocada em dessecador para arrefecimento. O rendimento do processo de produção de carvão foi obtido pela razão entre a massa de carvão e a massa inicial.

\subsection{Cominuiçãa e Densificação Energética}

Para evitar que partículas grandes prejudicassem a ação dos aglutinantes e as características finais dos briquetes, houve a cominuição do bagaço de laranja carbonizado. Para isto, o bagaço carbonizado foi moído (TE-633, TECNAL) e as partículas de carvão foram utilizadas para análises e para a produção dos briquetes. O processo de briquetagem foi realizado utilizando-se uma prensa manual uniaxial hidráulica e um molde cilíndrico. 
Os aglutinantes utilizados para a briquetagem foram: pectina com alto teor de metoxilação - 60\% (Pec-1), pectina com baixo teor de metoxilação - 30\% (Pec-2) e amido de milho. Foi variada a porcentagem do aglutinante na mistura com as partículas de carvão nas proporções de 5, 10 e 15\%. Entretanto para a análise de resistência a compressão mecânica, apenas os briquetes produzidos com $10 \%$ de aglutinante foram analisados, devido a questões econômicas relacionadas à própria verba da pesquisa, pois são testes caros. Os briquetes produzidos com as outras composições passaram por outras análises, algumas das quais já foram publicadas no meio científico nos trabalhos de Concentino et al. (2016), Zanella et al. (2016) e por Zanella et al. (2017).

A metodologia para a mistura entre partículas de carvão vegetal e aglutinante foi determinada em ensaios preliminares. Foi realizada a mistura manual entre as partículas de carvão vegetal, água e o aglutinante. Para as pectinas foram utilizadas a razão de 1:0,5 (m/m) entre carvão e água e essa mistura final seguiu para a densificação. Para o amido essa proporção foi de $1: 1$ e a mistura foi aquecida até cerca de $100{ }^{\circ} \mathrm{C}$, para ativação do aglutinante. Depois de obtida a pasta, a mistura foi destinada à formação dos briquetes. Uma força de compressão de 5 toneladas foi aplicada pela prensa hidráulica no briquete de seção transversal de $20 \mathrm{~cm}$, durante 1 minuto para cada ensaio realizado. Após, os briquetes passaram pelo processo de secagem, em uma estufa com circulação forçada de ar à temperatura de $80{ }^{\circ} \mathrm{C}$, até um teor de umidade final de 8 a 12\% (Fontes et al., 1989). Os valores utilizados nesta etapa foram determinados em testes preliminares.

\subsection{Análises}

Análise imediata: A análise imediata foi realizada para o carvão vegetal, para os aglutinantes e para os briquetes com $10 \%$ de aglutinantes. Esta análise permitiu a caracterização dos materiais, para o carvão, um alto teor de carbono fixo é desejável, por isso a importância destes testes. A análise de umidade higroscópica foi determinada utilizando o método gravimétrico, a $105{ }^{\circ} \mathrm{C}$, em estufa, até peso constante. Posteriormente foi determinado o teor de voláteis, que consiste em submeter a amostra à temperatura de $850{ }^{\circ} \mathrm{C}$ durante 7 minutos, em uma mufla. Para determinação das cinzas, a amostra, já sem umidade e voláteis, é colocada na mufla. A temperatura utilizada foi de $710{ }^{\circ} \mathrm{C}$ por $1 \mathrm{~h}$. Ao final da análise, restam somente as cinzas da amostra. Após a determinação dos teores de matéria volátil e de cinzas da amostra, o teor de carbono fixo é obtido por diferença, segundo a Eq.1. Todas as análises foram realizadas em triplicata.

$$
C F[\%]=100-(\text { Voláteis }[\%]+\text { Cinzas }[\%])
$$

Resistência à compressão mecânica: As análises de resistência à compressão foram realizadas em triplicata em uma máquina universal de testes (MTS). Os ensaios de compressão mecânica foram realizados aplicando-se uma força perpendicular a seção do briquete até que ocorresse a ruptura do briquete, visualizada graficamente pelo software instalado junto à máquina universal de testes. Os parâmetros utilizados foram: velocidade préteste, velocidade de teste e velocidade pós-teste (todas $0,3 \mathrm{~cm} / \mathrm{min}$ ) e carga de contato $(1000$ $\mathrm{kg}$ ). O valor das velocidades de teste foi baseado no trabalho de Quirino (1991). O software gera um gráfico da pressão exercida pela deformação sofrida pelo briquete.

\section{RESULTADOS E DISCUSSÃO}

\subsection{Análise Imediata}


Os valores obtidos para a análise imediata do carvão vegetal, dos aglutinantes utilizados e dos briquetes estão apresentados na Tabela 1.

Tabela 1 - Análise imediata dos materiais

\begin{tabular}{ccccc}
\hline Amostra & Umidade (\% b.u.) & Voláteis (\% b.s.) & Cinzas (\% b.s.) & C. F. (\% b.s) \\
\hline Carvão vegetal & $4,49 \pm 0,09$ & $37,95 \pm 1,91$ & $11,19 \pm 0,07$ & $50,86 \pm 1,16$ \\
Pec-1 & $8,19 \pm 0,02$ & $93,16 \pm 0,83$ & $4,66 \pm 0,03$ & $2,18 \pm 0,84$ \\
Pec-2 & $6,31 \pm 0,01$ & $81,79 \pm 1,39$ & $6,93 \pm 0,04$ & $11,29 \pm 1,43$ \\
Amido & $11,54 \pm 0,18$ & $90,04 \pm 0,53$ & - & $9,97 \pm 0,53$ \\
Carvão + Pec-1 & $2,75 \pm 0,04$ & $37,79 \pm 0,91$ & $11,56 \pm 0,84$ & $50,65 \pm 1,36$ \\
Carvão + Pec-2 & $4,18 \pm 0,30$ & $40,67 \pm 2,03$ & $11,79 \pm 1,29$ & $47,54 \pm 3,04$ \\
Carvão + Amido & $4,97 \pm 0,25$ & $54,51 \pm 1,45$ & $10,21 \pm 0,64$ & $32,28 \pm 0,89$ \\
\hline
\end{tabular}

Apesar dos aglutinantes apresentarem elevado teor de voláteis, apenas os briquetes produzidos com o amido apresentaram queda significativa no valor do carbono fixo quando comparados ao teor do carvão vegetal. Para os briquetes produzidos com as pectinas, esta característica não prevalece, mesmo sendo esperada. Este comportamento pode ter ocorrido devido ao fato de a mistura para a produção do briquete ser feita manualmente, e não apresentar homogeneidade similar. Verifica-se que não houve um aumento no teor de cinzas dos briquetes. Isto ocorre devido ao fato de que os aglutinantes possuem teor de cinzas menor (inexistente para o amido) que o carvão em sua composição. Neste trabalho, todas as amostras entre carvão vegetal e aglutinante sintetizadas destinam-se ao uso doméstico e comercial como biocombustível, pois apresentam elevado teor de cinzas (Santos, 2008).

\subsection{Resistência a Compressão Mecânica}

A Figura 1 traz a imagem do briquete produzido com $10 \%$ de amido antes do ensaio e imediatamente após a ruptura do corpo de prova.

Figura 1 - Briquete com 10\% de amido antes (esq.) e após (dir.) o ensaio de compressão.
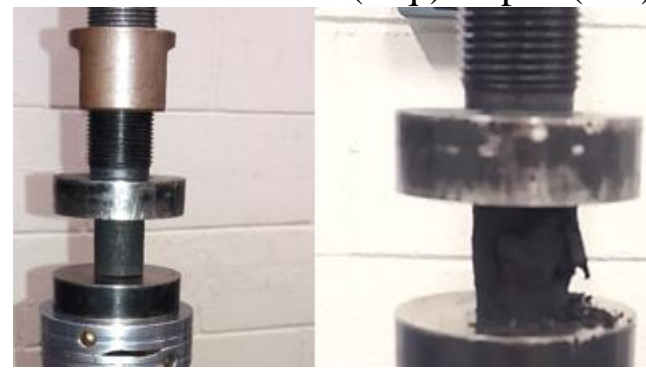

Os resultados obtidos pelos ensaios de compressão são expressos pelos valores da força aplicada a uma determinada área (Stress) necessária para produzir uma deformação (Strain). Os valores dos picos de pressão e o máximo de deformação para cada ensaio assim como a média são apresentados na Tabela 2. A partir de cada conjunto de ensaios de um aglutinante foi gerada uma curva média Stress $\times$ Strain, apresentadas na Figura 2.

Tabela 2 - Valores Stress $\times$ Strain dos briquetes de carvão vegetal.

\begin{tabular}{c|cc|cc|cc}
\hline \multirow{2}{*}{ Ensaio } & \multicolumn{2}{|c|}{ Amido } & \multicolumn{2}{c|}{ Pec-1 } & \multicolumn{2}{c}{ Pec-2 } \\
& Stress (MPa) & Strain (\%) & Stress (MPa) & Strain (\%) & Stress (MPa) & Strain (\%) \\
\hline $\mathbf{1}$ & 3,22 & 12,6 & 2,43 & 11,02 & 1,82 & 12,08 \\
$\mathbf{2}$ & 3,03 & 10,49 & 2,21 & 10,87 & 1,82 & 13,15 \\
$\mathbf{3}$ & 3,83 & 9,65 & 1,71 & 10,58 & 1,7 & 14,17 \\
\hline Média & $3,36 \pm 0,42$ & $10,91 \pm 1,52$ & $2,12 \pm 0,37$ & $10,82 \pm 0,22$ & $1,78 \pm 0,07$ & $13,13 \pm 1,05$ \\
\hline
\end{tabular}


Figura 2 - Curva Stress $\times$ Strain média aplicadas aos briquetes de carvão vegetal

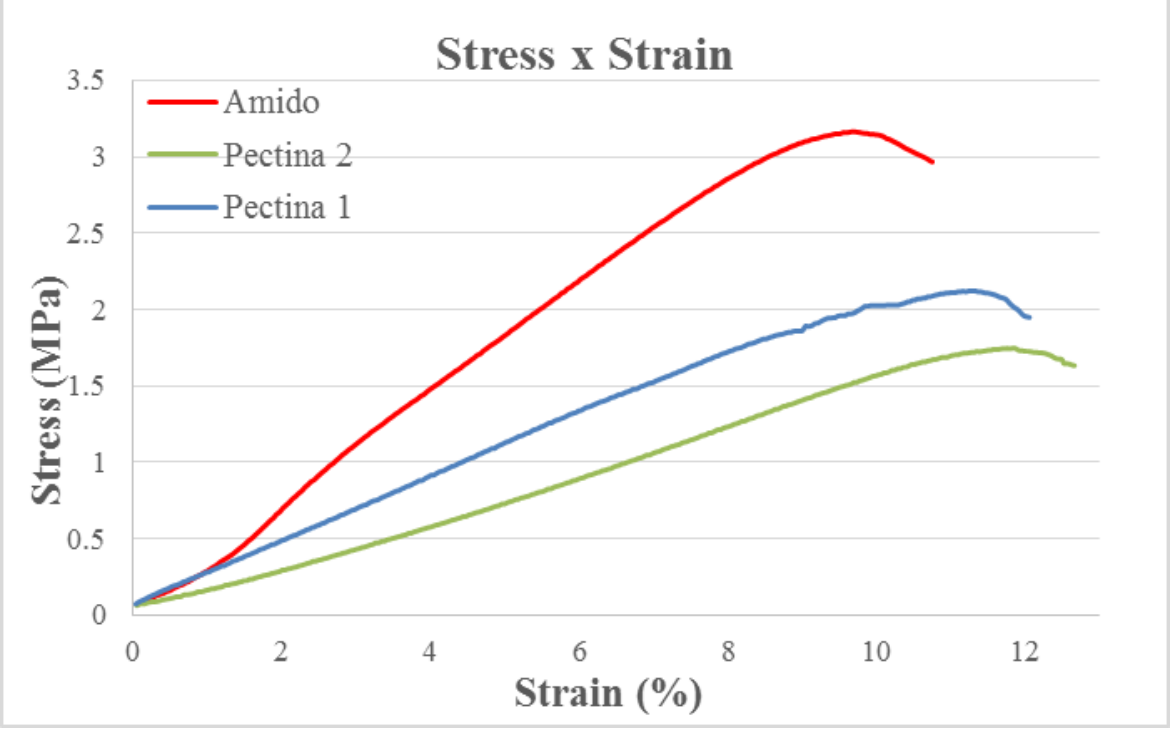

Há uma diferença notável entre a tensão máxima (Stress) entre os briquetes produzidos com o aglutinante amido e com as pectinas, apesar de os valores da deformação máxima (Strain) ser semelhantes. Isto significa que os espaços intersticiais (porosidade) entre os briquetes são semelhantes, pois sofreram um deslocamento parecido, entretanto, após atingirem a compactação máxima, os briquetes de amido mostraram-se mais resistentes. Resultados semelhantes foram encontrados por Rubio et al. (1999). O valor mínimo aceito para a tensão máxima de um briquete é de 1,5 MPa (Borowski, 2011). Todos os briquetes produzidos neste trabalho têm resistência superior a este valor, sendo que o briquete produzido com amido possui mais que o dobro de tensão máxima. Portanto, indica-se o amido como aglutinante para a produção deste tipo de briquete.

A partir da curva Stress $\times$ Strain média de cada aglutinante é possível obter o módulo de Young que relaciona a tensão aplicada e a deformação sofrida pelo corpo de prova. Também chamado de módulo de elasticidade, este caracteriza a rigidez do material, e é obtido na primeira fase de deformação, chamada de deformação elástica, fase na qual o material deforma, mas retorna às dimensões originais caso a tensão aplicada seja retirada. $\mathrm{O}$ módulo de elasticidade é proporcional à força de atração entre os átomos, portanto quanto maior este módulo, maior resistência possui o briquete e, portanto, mais eficiente é o aglutinante. A Tabela 3 apresenta os valores obtidos do módulo de Young.

Tabela 3 - Módulos de Young dos briquetes

\begin{tabular}{|c|c|c|c|}
\hline $\begin{array}{c}\text { Mod. Young } \\
\text { (MPa) }\end{array}$ & Amido & Pec-1 & Pec-2 \\
\cline { 2 - 4 } & $47,23 \pm 6,24$ & $23,18 \pm 1,95$ & $17,55 \pm 1,44$ \\
\hline
\end{tabular}

\section{CONCLUSÕES}

Neste estudo, os resultados mostraram, dentro do domínio estudado, que o bagaço de laranja é uma biomassa com elevado potencial para a produção de briquetes de carvão, utilizando o amido como aglutinante. As variáveis medidas neste trabalho, em especial o teor de carbono fixo, de cinzas e tensão máxima, fazem com que os briquetes possam ser destinados para aplicação em uso doméstico e comercial, como biocombustível. 


\section{REFERÊNCIAS}

ALHO, C. F. B. V. Efeito da temperatura final de pirólise na estabilidade de biocarvão produzido a partir de madeira de Pinus sp. e Eucalyptus sp. 58 (Mestrado). Ciências Ambientais e Florestais, UFRRJ, Seropédica - RJ. 2012.

BOROWSKI, G. Possibilities of utilization of energy briquettes. EEEIC, v. 1 (27). 2011.

CONCENTINO, V. O.; ZANELLA, K.; TARANTO, O. P. Percentage Influences of Pectin on the Friability Index of Orange Waste Charcoal Briquettes. XXIV Congresso de Iniciação Científica da UNICAMP, 2016.

DE OLIVEIRA, R. R. L. Moldagem de briquetes com finos de carvão vegetal aglutinados com parafina: Caracterização de algumas propriedades. 80 (Mestrado). Ciência dos Materiais, UFSC, Sorocaba - SP. 2013.

DIAS, J. M. C. D. S. et al. Produção de briquetes e péletes a partir de resíduos agrícolas, agroindustriais e florestais. 2012.

FONTES, P. J. P. D.; QUIRINO, W. F.; ARAKARI, E. O. Aglutinante para briquetagem de carvão vegetal. Brasília - DF: Laboratório de produtos florestais, p.1-14.1989.

QUIRINO, W. F. Características e índice de combustão de briquetes de carvão vegetal. (Mestrado). Ciências Florestais, Universidade de São Paulo, Brasília - DF. 1991.

RUBIO, B.; IZQUIERDO. M. T.; SEGURA. E. Effect of binder addition on the mechanical and physicochemical properties of low rank coal char briquettes, Carbon, v. 37, 1999.

SANTOS, I. D. Influência dos teores de lignina, holocelulose e extrativos na densidade básica, contração da madeira e nos rendimentos e densidade do carvão vegetal de cinco espécies lenhosas do cerrado. Dissertação (Mestrado em Engenharia Florestal) Universidade de Brasília, Brasília, 2008.

TIENNE, L.; DESCHAMPS, M.; ANDRADE, A. Produção de carvão e subprodutos da pirólise da casca e do bagaço da laranja (Citrus sinensis). Biomassa \& Energia, 2004.

TUMULURU, J. S. et al. A review of biomass densification systems to develop uniform feedstock commodities for bioenergy application. Biofpr, v. 5, n. 6, p. 683-707, 2011.

ZANELLA, K.; CONCENTINO, V. O., TARANTO, O. P. Influence of the type of mixture and concentration of different binders on the mechanical properties of "green" charcoal briquettes. Chem. Eng. Trans., v. 57, 2017 (In press).

ZANELLA, K; GONÇALVES, J. L.; TARANTO, O. P. Charcoal Briquette Production Using Orange Bagasse and Corn Starch. Chem. Eng. Trans., v. 49, p. 313-318, 2016. 